\title{
Tratamiento del rechazo agudo hiperinmune con plasmaféresis y rituximab. Nuestra experiencia
}

\author{
Raquel Pérez Uceta - Esther Llorente Sansano - Joseba Iñaki Agüero Jurado - Gema Briceño Sánchez \\ $M^{\mathrm{a}}$ Ángeles Gálvez Velasco - $\mathbf{M}^{\mathrm{a}}$ Isabel Bravo Moreno
}

Enfermeras/os

Unidad de Hemodiálisis, Hospital Virgen de la Salud. Toledo

\section{Introducción}

El trasplante renal consiste en la extracción de un riñón de un individuo sano y su colocación en un paciente con insuficiencia renal crónica terminal ${ }^{1}$.

El rechazo inmunológico es la principal complicación tras el trasplante. Se denomina rechazo al conjunto de manifestaciones clínicas, funcionales, anatomopatológicas, que pueden aparecer en un receptor de trasplante renal, como consecuencia de la activación del sistema inmune contra el injerto. El rechazo puede aparecer desde el momento de revascularización del órgano hasta años más tarde².

La incidencia del rechazo dependerá esencialmente de dos factores: las características del receptor y el tratamiento inmunosupresor utilizado. En general se acepta que un $30-40 \%$ de los pacientes desarrollan algún episodio de rechazo en el trasplante inmediato (3 primeros meses) ${ }^{1}$.

En la mayoría de los protocolos se utilizan como tratamiento convencional bolos de metil-prednisolona a dosis que varían entre 250 y $1.000 \mathrm{mg} /$ día, durante 3-4 días. Con esta pauta se consigue respuesta entre el $60-70 \%$ de los casos. En el resto de los casos se habla de rechazo corticoresistente ${ }^{2}$.

\footnotetext{
Correspondencia:

Raquel Pérez Uceta

Unidad de Hemodiálisis del Complejo Hospitalario de Toledo

Avda. Barber No 26. 45005 Toledo

E-mail: caosina28@hotmail.com
}

La Plasmaferesis ha sido recientemente introducida en el tratamiento del rechazo agudo del trasplante renal resistente al tratamiento convencional con esteroides ${ }^{3}$.

La aféresis puede definirse como una modalidad terapéutica que consiste en la extracción de un volumen determinado de plasma (de 2 a 5 litros) con el fin de eliminar aquellos patógenos considerados responsables de una enfermedad o bien sus manifestaciones clínicas.

El recambio plasmático mediante filtración a través de membranas se realiza mediante el montaje de un circuito extracorpóreo, similar al de la hemodiálisis, intercalando un filtro de fibra hueca, de celulosa, polipropileno, plimetilmetacrilato, aleación de polímeros, polipropileno y polivinilclorido 4 .

La plasmaferesis se utiliza en la terapia de diversas patologías, especialmente en procesos reumatológicos, neurológicos, inmunológicos y hematológicos ${ }^{5}$.

El rituximab es un anticuerpo monoclonal que se une específicamente al antígeno de superficie CD20 de los linfocitos $B^{6}$.

Teniendo en cuenta que la producción patológica de anticuerpos es la característica de numerosas enfermedades sistémicas que afectan al riñón, rituximab ha comenzado a emplearse en una gran variedad de estas patologías, aunque el mecanismo exacto por el cual actúa no está claramente definido. En concreto, este anticuerpo monoclonal se ha empleado, en otros trastornos, en la glomerulonefritis membranosa, la crioglobulinemia, el lupus eritematoso, las vasculitis 
asociadas a ANCA, la hialinosis segmentaria y focal, en el contexto del trasplante renal para tratamiento del rechazo humoral, etc. Sin embargo las series publicadas hasta ahora en este tipo de trastornos son pequeñas, sin estudios controlados y probablemente no se han publicado aquellos casos con resultados negativos. Son necesarios estudios controlados aleatorizados que garanticen las diversas indicaciones del rituximab ${ }^{7}$.

Con este estudio pretendemos dar a conocer nuestra experiencia con el uso de este procedimiento en el tratamiento del rechazo agudo hiperinmune en nuestra unidad, considerando la escasez de datos a nivel nacional.

\section{Objetivo}

El objetivo principal de nuestro estudio es mostrar nuestra experiencia en el uso de esta técnica y dar a conocer nuestros resultados, así como los aspectos clínicos más relevantes del procedimiento.

\section{Material y método}

Hemos realizado un estudio observacional, descriptivo, longitudinal, retrospectivo que encuadramos en las llamadas series de casos.

Se han estudiado a todos los pacientes que tras recibir un trasplante renal han presentado un diagnostico de rechazo agudo y que han sido tratados con plasmaferesis y rituximab desde el 1-1-2009 al 31-12-2010.

Para ello hemos llevado a cabo una revisión bibliográfica, de las historias clínicas, de las graficas de plasmaferesis y las observaciones de enfermería.

\section{Caso Clínico 1}

Varón de 32 años, con enfermedad renal crónica secundaria a Síndrome de Good-Pasture, que Ilevaba 10 años en programa de hemodiálisis. Con un trasplante previo perdido por rechazo crónico.

Se realiza el segundo trasplante el 29-4-2009. Presentando 3 incompatibilidades con el donante.

Al séptimo día postrasplante, presenta oliguria brusca y febrícula con aumento de resistencias vasculares en doppler renal, por lo que se inicia tratamiento con choque de esteroides, gammaglobulina hiperinmune, plasmaferesis y rituximab.

El paciente presento una evolución favorable, recuperando la función renal y diuresis espontanea el día veintidós postrasplante, quedando la creatinina al alta en $2,1 \mathrm{mg} / \mathrm{dl}$.

\section{Caso Clínico 2}

Varón de 37 años en tratamiento con hemodiálisis desde 1990, por enfermedad renal crónica no filiada, con dos trasplantes previos, perdidos por rechazo crónico.

En el tercer trasplante realizado el 24 -5-2009 en el Hospital 12 de 0ctubre de Madrid presento signos de rechazo agudo humoral al séptimo día postraspalnte. Tratado con esteroides, gammaglobulina hiperinmune y 7 sesiones de plasmaferesis. Siendo la creatinina al alta de 1,6 mg/dl.

El 20-8-2009 se confirma un nuevo episodio de rechazo agudo. Se inicia el tratamiento esta vez en nuestra unidad, con esteroides, gammaglobulina hiperinmune, plasmaferesis y rituximab. Se reinicia la función renal, siendo la creatinina al alta de $1,23 \mathrm{mg} / \mathrm{dl}$.

\section{PARÁMETROS VALORADOS}

Datos sociodemográficos.

Tipo de rechazo.

Número de sesiones de plasmaferesis.

Tipo de líquido de reposición y cantidad.

Premedicacion.

Efectos adversos de la plasmaferesis.
Dosis de rituximab.

Número de sesiones de rituximab.

Efectos secundarios del rituximab.

Medicación inmunosupresora.

Evolución del rechazo.

Tabla 1. Parámetros valorados 


\section{Caso Clínico 3}

Varón de 48 años, parapléjico desde 1992 por lesión en D7-D8. Inicia tratamiento con hemodiálisis en 2007 por deterioro de la función renal.

Sin trasplantes previos, presenta 4 incompatibilidades con el donante. (Poner incompatibilidades).

Tras el trasplante el paciente presenta anuria por lo que se le realiza una sesión de hemodiálisis por sobre carga de volumen.

A las $48 \mathrm{~h}$ presenta mal estado general, junto con pico febril, hipotensión severa y mialgias dorsales. Se le realiza doppler renal urgente donde se observa inversión del flujo venoso. Se le realiza revisión quirúrgica urgente comprobándose la viabilidad del injerto así como la permeabilidad de arteria y vena renal.

Se ingresa en UVI por shock séptico y alta sospecha de rechazo agudo humoral necesitando intubación orotraqueal y hemofiltración veno-venosa continua. Tras ese doble diagnostico, deciden minimizar la inmunosupresión en espera de la respuesta de los antibióticos. Se inicia el tratamiento con plasmaferesis, rituximab y gammaglobulina intravenosa. A los 15 días postrasplante comienza con diuresis espontaneas disminuyendo la creatinina a $1,36 \mathrm{mg} / \mathrm{dl}$ al alta.

\section{Sesiones de plasmaferesis:}

Las sesiones de plasmaferesis las realizamos con el monitor Multifiltrate y el plasmafiltro Plasmaflux.

El circuito se preparo con $1.000 \mathrm{cc}$ de suero fisiológico y 5000 u.i. de heparina sódica al $1 \%$ según el protocolo de nuestra unidad.
El acceso vascular utilizado fue el que cada paciente tenía para recibir sus sesiones de hemodiálisis. En estos casos dos fistulas y un catéter.

El principal liquido de reposición utilizado fue albumina al 5\%. Utilizando ocasionalmente plasma fresco congelado.

Como premedicación usamos Polaramine, Zantac y Gluconato cálcico al 10\%. Y ocasionalmente Urbason $40 \mathrm{mg}$. Coincidiendo esto con la reposición con plasma fresco.

La anticoagulación utilizada fue heparina sódica al $1 \%$ en bolos de 1.000 a 5.000 u.i. Pero no fue necesaria en todas las sesiones.

En cuanto a las complicaciones acaecidas debemos reseñar que solo se produjeron en dos ocasiones. Ambas menores. En una ocasión se coaguló el circuito y el plasmafiltro y en otra se produjo hemostasia prolongada.

\section{Rituximab}

Todos los pacientes recibieron 4 sesiones de rituximab con una dosis que varió entre 375 y $700 \mathrm{mg} / \mathrm{m}^{2}$ diluidos en 500cc de suero fisiológico. La primera dosis se administra en $\mathrm{lh}$ y si no hay reacciones el resto de sesiones en 30 min. Como premedicación usamos Paracetamol y Polaramine.

Tan solo en una ocasión se produjeron efectos adversos (prurito, disnea, opresión,...) que cedieron con medicación sintomática, reanudando sin problemas la administración del rituximab.

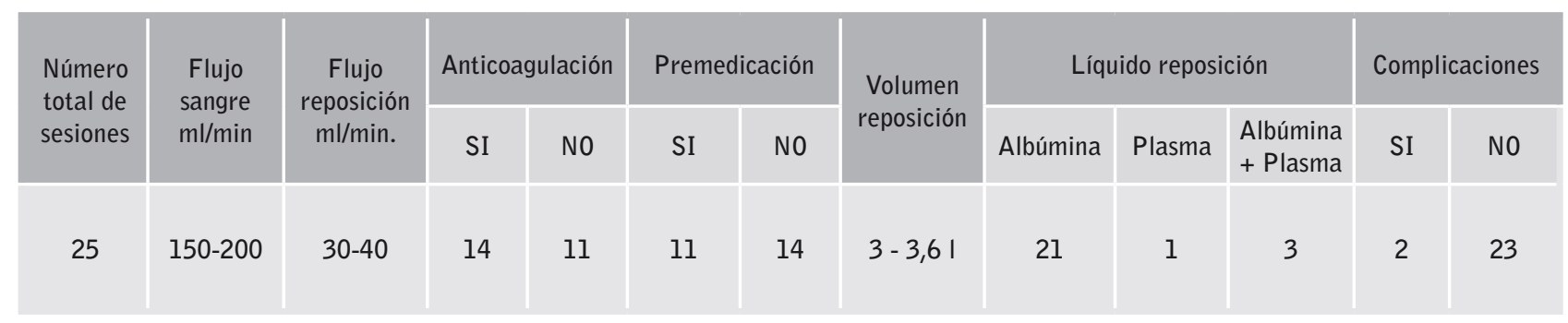

Tabla 2. Tabla Resumen de las Sesiones de Plasmaferesis. 


\begin{tabular}{|l|c|c|c|}
\hline & CASO 1 & CASO 2 & CASO 3 \\
\hline Terapia inicial & $\begin{array}{c}\text { Timoglobulina } \\
\text { Esteroides } \\
\text { Micofenolato } \\
\text { Tacrolimus }\end{array}$ & $\begin{array}{c}\text { Timoglobulina } \\
\text { Esteroides. } \\
\text { Micofenolato } \\
\text { Tacrolimus }\end{array}$ & $\begin{array}{c}\text { Esteroides } \\
\text { Micofenolato } \\
\text { Tacrolimus }\end{array}$ \\
\hline Biopsia & SI & SI & SI \\
\hline Tipo de rechazo & Humoral & Humoral & Humoral \\
\hline$N^{\circ}$ sesiones Plasmaféresis & 13 & 6 & 6 \\
\hline Reversión del rechazo & SI & SI & SI \\
\hline Creatinina tras Plasmaféresis & 4.9 & 1.07 & 1.53 \\
\hline Dosis de Rituximab administrada & $700 \mathrm{mg}$ & $375 \mathrm{mg}$ & $600 \mathrm{mg}$ \\
\hline$N^{\circ}$ de sesiones de Rituximab & 4 & 4 & 4 \\
\hline
\end{tabular}

Tabla 3. Tabla Resumen de los casos

\section{Resultados}

1. En el periodo de estudio se han realizado en nuestro servicio 25 sesiones de plasmaféresis combinados con tratamiento de rituximab.

2. Todos los pacientes estudiados son varones con una edad media de 39 años.

3. El número de sesiones realizadas por paciente osciló entre 6 y 13 sesiones siendo la media 8,33 sesiones.

4. Todas las sesiones de plasmaferésis se realizaron a través del acceso vascular que disponían para sus sesiones de hemodiálisis.

5. El flujo de sangre se mantuvo entre 150 y $200 \mathrm{ml} /$ min y el de reposición entre 30 y $40 \mathrm{ml} / \mathrm{min}$.

6. La dosis administrada de rituximab fue de 375$700 \mathrm{mg} / \mathrm{m}^{2}$.

7. Los efectos adversos acaecidos fueron mínimos. En una ocasión se produjo la coagulación del circuito y del plasmafiltro. Y en otra hemostasia prolongada tras la sesión de plasmaferesis. En cuanto a la administración de rituximab en una ocasión apareció disnea, prurito y opresión que cedieron con medicación sintomática pudiendo reanudar la administración de rituximab.

\section{Discusión}

- Todos los pacientes estudiados tuvieron una evolución favorable en la que el rechazo revirtió, con escasos efectos indeseables.

- La mejoría experimentada en los casos estudiados permite atribuir un efecto beneficioso a la plasmaferesis combinada con rituximab aunque debido al escaso número de pacientes estudiados hasta ahora esta afirmación no es concluyente.

Recibido: 20 Diciembre 2011

Revisado: 10 Enero 2012

Modificado: 10 Febrero 2012

Aceptado: 15 Febrero 2012

\section{Bibliografía:}

1. Andreu Periz L, Force Sanmartin E. 500 cuestiones que plantea el cuidado del enfermo renal. $2^{\mathrm{a}}$ Edición. Barcelona: Masson; 2001.

2. Andreu Periz L, Force Sanmartin E. La enfermería y el trasplante de órganos. Madrid: Médica Panamericana; 2004. 
3. Herrera, L; Soto, I; Sequí, M.J.; Fernández, A. Efecto de la plasmaféresis en el tratamiento del rechazo agudo resistente al tratamiento convencional. En: El libro de ponencias: $8^{a}$ Reunión Nacional de la Sociedad Española de ATS de nefrología. Oviedo 12-15 de octubre, 1983.p.51-57. Disponible en : hhtp://:www.seden.org.

4. De la Vara Almonacid, J.A.; García Estévez, S, et al. Plasmaféresis como tratamiento de enfermedades renales. Experiencia de 16 años en un centro. En: El libro de ponencias: XXXII Congreso Nacional de la Sociedad Española de Enfermería Nefrológica.
Cádiz 3-6 de octubre, 2007. Barcelona: Hospal; 2007. p. 99-102.

5. Anaya F. Aféresis Terapéutica. Madrid. Norma- Capitel.2005.

6. Sastre A, Baños M, Seco M, Gómez Huertas E. Recidiva de vasculitis en trasplante renal tratada con rituximab. Nefrología. 2007; 27 (5): 645-646.

7. Fernández-Fresnedo $G$, López hoyos $M$, Arias $M$. Rituximab en el tratamiento de las enfermedades glomerulares. NefroPlus. 2009; 2(3): 24-33. 